\title{
KONSEP COMMUNITY BASED TOURISM SEBAGAI STRATEGI PENGEMBANGAN KAIN SONGKET SIDEMEN DI BALI
}

\author{
Ni Kadek Ajeng Wangi Bhuanaputri, I Putu Ryan Dharma Putra, I Made Indra \\ Wahyudi, Ni Made Ayu Cantika Ratih, Marcellino Dominicius Adam \\ Institut Pariwisata dan Bisnis Internasional, Bali Indonesia \\ Email: ajengwangibhuanaputri@gmail.com, riandharmaputra9@gmail.com, \\ wahyuindra.iw@gmail.com, cantikaratih9@gmail.com, \\ marcellinoda33@gmail.com,
}

\begin{abstract}
Abstrak
Kain Songket Sidemen yang autentik dalam mendukung pariwisata berkelanjutan di tengah pandemi COVID-19 di Desa Sidemen, Kecamatan Sidemen. Kain Songket Sidemen merupakan kain khas tradisional dengan proses pembuatan, motif kain yang kental dengan budaya Bali dan penuh makna. Kain Songket Sidemen ini menjadi produk wisata budaya khas Desa Sidemen. Metode penelitian yang digunakan adalah metode penelitian deskriptif dengan input data kualitatif. Teknik pengumpulan data dilakukan dengan observasi partisipatif, dan wawancara mendalam dengan yang terdiri dari Pengurus Desa Sidemen, pengerajin Kain Songket Sidemen, dan penjual Kain Songket Sidemen sebagai data primer, serta studi dokumentasi sebagai data sekunder. Strategi pengembangan Kain Songket Sidemen sebagai produk wisata budaya dengan konsep Community Based Tourism serta strategi Stabilitas, merupakan strategi untuk meningkatkan nilai-nilai kearifan budaya lokal Bali, meningkatkan pemasaran dan peran pemerintah dan masyarakat, serta meningkatkan kebutuhan pasar. Maka dari itu Kain Songket Sidemen perlu dikembangkan untuk mendukung kelestarian budaya dan menerapkan community based tourism dalam pengembangannya sehingga dapat meningkatkan kualitas pariwisata Bali upaya penerapan pariwisata berkelanjutan di era pandemi COVID19. Tujuan penelitian ini, yaitu mengindentifikasi potensi dari pengembangan produk wisata budaya Kain Songket Sidemen dalam mendukung pariwisata berkelanjutan dengan menerapkan konsep community based tourism serta strategi pengembangan penjualan produk wisata budaya Kain Songket Sidemen yang autentik dalam mendukung pariwisata berkelanjutan di tengah pandemi COVID-19 di Desa Sidemen, Kecamatan Sidemen.
\end{abstract}

Kata Kunci: kain songket sidemen; community based tourism; strategi pengembangan

\section{Abstract}

Authentic Songket Sidemen fabric in supporting sustainable tourism in the midst of the COVID-19 pandemic in Sidemen Village, Sidemen Sub-district. The research method used is descriptive research method with qualitative data input. Data collection techniques are conducted with participatoryobservations, and in-depth interviews with those consisting of Sidemen Village Administrators, Songket Sidemen Fabric craftsmen, and Sellers of Songket Sidemen Fabric as primary data, as well as

$\begin{array}{ll}\text { How to cite: } & \text { Bhuanaputri, N. K. A. W., et al. (2021) Konsep Community Based Tourism Sebagai Strategi } \\ & \text { Pengembangan Kain Songket Sidemen Di Bali, Syntax Idea, 3(8), https://doi.org/10.36418/syntax- } \\ & \text { idea.v6i8.1412 } \\ \text { E-ISSN: } & 2684-883 X \\ \text { Published by: } & \text { Ridwan Institute }\end{array}$


documentation studies as secondary data. Thestrategy of developing Kain Songket Sidemen as a cultural tourism product with the concept of Community Based Tourism and Stability strategy, is a strategy to increase the values of local Balinese cultural wisdom, increase marketing and the role of government and society, as well as increase market needs. Therefore, Kain Songket Sidemen needs to be developed to support cultural sustainability and implement community based tourism in its development so as to improve the quality of Bali tourism efforts to implement sustainable tourism in the era of the COVID-19 pandemic. Songket Sidemen is a traditional typical fabric with a manufacturing process, cloth motifs that are thick with Balinese culture and full of meaning. This Sidemen Songket cloth is a cultural tourism product typical of Sidemen Village. The purpose of this study is to identify the potential of developing Songket Sidemen cultural tourism products in supporting sustainable tourism by applying the concept of community based tourism and a strategy for developing sales of authentic Songket Sidemen cultural tourism products in supporting sustainable tourism in the midst of the COVID-19 pandemic in Sidemen Village. District Sidemen

Keywords: kain songket sidemen, community based tourism, development strategy

\section{Pendahuluan}

Pariwisata berbasis masyarakat atau Community Based Tourism merupakanpelibatan masyarakatdengan kepastian manfaat yang diperoleh oleh masyarakat melalui upaya perencanaan pendampingan yang membela masyarakat lokal.serta kelompok lain yang memiliki antusiasatau minat kepada kepariwisataan, dengan pengelolaan pariwisata yang memberi peluang lebih besar untuk mewujudkan kesejahteraan masyarakat setempat. Pariwisata berbasis masyarakat berkaitan dengan adanya partisipasi yang aktif dari masyarakat sebagai pengelola dalam pembangunan kepariwisataan yang ada (Puspitasari, Prayudi, \& Rochayanti, 2020). Konsep Comunity Based Tourism ini perlu didukung dengan konsep pemasaran yang efektif dan efisien dalam upaya penerapan pariwisata berkelanjutan. Berdasarkan hal tersebut, dapat dinyatakan bahwa Community Based Tourism adalah perkembangan pariwisata dikelola oleh masyarakat dalam rangka mendukung upaya dalam meningkatkan produktivitas masyarakat. Saat ini kemajuan IPTEK, pemasaran sebuah produk wisata pun sudah mulai menggunakan aplikasi kekinian dan mudah diakses oleh berbagai macam kalangan, segala kegiatan pariwisata diharuskan mengikuti jaman yang berbasis digital sejalan dengan yang dinyatakan oleh (Chen, Su, \& Widjaja, 2016) salah satu cara untuk meningkatkan industri pariwisata adalah dengan memanfaatkan kemajuan teknologi informasi dan komunikasi (seperti: internet of things, cloud computing, big data, dan artificial intelligence). Destinasi digital adalah konsep wisata yang dipersiapkan untuk generasi milenial dengan menyajikan tempat wisata yang unik dan instagramable. Pariwisata berbasis dengan kearifan budaya lokal yang akan dikembangakan melalui sistem digital, dipengaruhi oleh era pandemi COVID-19. Pandemi COVID-19 dipercaya akan membawa dunia pada new normal tidak terkecuali Bali yang selama ini mengandalkan sektor pariwisata. Prinsip new normal adalah kegiatan pariwisata 
Ni Kadek Ajeng Wangi Bhuanaputri, I Putu Ryan Dharma Putra, I Made Indra Wahyudi, Ni Made Ayu Cantika Ratih, Marcellino Dominicius Adam

memanfaatkan teknologi dan penerapan protokol kesehatan sebagai poin penting untuk membuat wisatawan nyaman. Wisatawan pada umumnya jika berwisata membeli souvenir atau produk wisata dari suatu destinasi wisata yang dikunjunginya. Dalam hal ini erat kaitannya dengan partisipasi masyarakat untuk membuat produk wisata yang autentik berbasis kearifan budaya lokal, serta informasi mengenai produk wisata atau pembelian produk wisata yang dapat diakses kapan saja melalui e-commerce (penggunaan aplikasi online shop). Penjualan produk yang memiliki dua sistem yaitu secara langsung dan tidak langsung. Di tengah pandemi ini seluruh kegiatan lebih mudah berjalan dengan sisitem tidak langsung yaitu daring (dalam jaringan).

Dewasa ini perkembangan pariwisata berkelanjutan berbasis kearifan budaya lokal dengan pemanfaatan teknologi sangat berkembang dengan pesat, adanya trend yang sangat digemari wisatawan, khususnya wisatawan millenial lebih menikmati kegiatan wisata yang bersifat autentik dan orisinalitas dari suatu kebudayaan yang ada dan dengan mudah untuk diakses melalui teknologi. Bali sebagai primadona dari destinasi pariwisata di Indonesia, yang dimana tentunya dilengkapi dengan fasilitas dan dituntut untuk selalu bergerak maju dalam mengembangkan sumber daya alam, sumber daya manusia yang berkompeten hingga infrastuktur. Pembangunan dan penataan wilayah Bali ke depan, Pemerintah Provinsi Bali mulai menyiapkan sejumlah regulasi untuk terus melakukan pelestarian budaya di era globalisasi (Grüning et al., 2018). Adapun salah satu Desa di Karangasem memiliki potensi pariwisata yaitu Desa Sidemen, Kecamatan Sidemen. Potensi Sidemen yang dimiliki dan dijadikan produk wisata berbasis kearifan budaya lokal yaitu Kain Songket Sidemen. Kain Songket yang dimliki oleh Desa Sidemen sudah dikenal oleh banyak wisatawan. Dalam pengembangan produk wisata budaya untuk mendukung Sustainable Tourism harus mengetahui syarat-syarat yang harus dipenuhi agar kegiatan wisata dianggap berkelanjutan yakni: environmentally sustainable, socially and culturally acceptable, economically viable technologically appropriate (Anoma, Mahagangga, Ariwangsaa, \& Wulandari, 2019.). Perkembangan pariwisata berbasis kearifan budaya lokal tidak luput dari partisipasi masyarakat sekitar. Seperti yang dikatakan Hausler (2005) dalam Tourism Forum International mendefinisikan CBT (Community Based Tourism) sebagai bentuk pariwisata yang memberikan kesempatan kepada masyarakat lokal untuk mengontrol dan terlibat dalam manajemen dan pengembangan pariwisata. Melalui konsep CBT (Community Based Tourism) dapat menciptakan pariwisata berkelanjutan (Sustainable Tourism) dalam pengembangan kawasan wisata. Pengembangan pariwisata berkelanjutan dianggap sebagai prasyarat utama dalam pembangunan pariwisata ke depan. Dengan demikian, diperlukannya suatu upaya berupa riset yang dimana menganalisis pengembangan Kain Songket Sidemen sebagai produk pariwisata budaya dengan menerapkan konsep community based tourism di era pandemi COVID-19 untuk mengembangkan produk wisata berbasis kearifan budaya lokal serta mewujudkan masyarakat yang produktif dan terlibat aktif dalam mengembangkan dunia pariwisata dengan pemanfaatan teknologi dan informasi untuk mengurangi keterbatasan yang dimiliki oleh masyarakat dalam mendukung pariwisata berkelanjutan di Desa Sidemen, 
Kecamatan Sidemen. Beberapa peneliti terdahulu yang berfokus pada analisis skala ekonomis pada industri Kain Songket Sidemen, seperti dari (Kade Ayu Karsani dan I Gusti Bagus Indrajaya, 2018) dalam penelitiannya yang diterbitkan berjudul "Analisis Skala Ekonomis Pada Industri Kain Songket di Desa Sidemen Kabupaten Karangasem" menguraikan tentang perubahan industri Kain Songket Sidemen yang sangat dipengeruhi oleh skala ekonomis. Dalam penelitian ini diuraikan tentang pengaruh dari sifat produksi Kain Songket Sidemen. Sedangkan artikel ini lebih fokus pada pembahasan dalam menganalisa pengembangan Kain Songket Sidemen dengan konsep peran masyarakat lokal (Community Based Tourism) di era pandemic COVID-19.

\section{Metode Penelitian}

Penelitian dilaksanakan di Desa Sidemen, Kecamatan Sidemen, Kabupaten Karangasem, Bali. Penelitian ini dilakukan mulai 19 Juli-21 Juli 2021. Menurut (Sugiyono, 2013) untuk mendapatkan data yang diharapkan, ada 4 metode pengumpulan data yang penulis lakukan, yaitu sebagai berikut, Observasi Partisipatif, yaitu pengamatan langsung sesuai dengan protokol kesehatan COVID-19 untuk memperoleh informasi mengenai pengembangan Kain Songket Sidemen Bali sebagai produk wisata budaya upaya penerapan pariwisata berkelanjutan di era pandemi COVID-19, sebagai data primer, Wawancara mendalam, yaitu cara yang digunakan untuk mendapatkan data primer berupa informasi secara lisan dari informan, Studi Dokumentasi, dalam penelitian ini studi dokumentasi dilakukan untuk menganalisis teori-teori dasar serta konsep yang relevan dalam penelitian ini serta salah satu cara untuk memperoleh data dan gambaran yang dapat mendukung penelitian ini. Metode yang digunakan yaitu metode empirik dengan pendekatan kualitatif.

\section{Hasil dan Pembahasan}

1. Konsep Community Based Tourism di Bali sebagai Strategi Kain Songket Sidemen Pengembangan Kain Songket Sidemen sebagai produk wisata budaya di Desa Sidemen didukung penuh oleh masyarakat setempat yang terlibat aktif dalam proses produksi hingga pemasaran dengan mengaplikasikan sistem digital. Berdasarkan hasil wawancara dengan Ibu Jero Widiari selaku distributor Kain Songket Sidemen menyatakan bahwa, sejauh ini dengan memanfaatkan digital sangat berpengaruh dalam pengembangan Kain Songket Sidemen di era pandemi COVID-19, hal ini dibuktikan dengan adanya pemasaran Kain Songket Sidemen di beberapa daerah di Bali yaitu Klungkung, Negara, Denpasar, luar Bali yaitu Kalimantan, Sulawesi bahkan luar negeri yaitu Jepang, Singapore, Thailand. Dalam hal ini masyarakat Desa Sidemen sangat mendukung pengembangan Kain Songket Sidemen dengan konsep Community Based Tourism. Konsep community based tourism dalam proses pembuatan keputusan selalu melibatkan masyarakat lokal khususnya terkait dengan pendapatan, kesempatan kerja, dan terutama pelestarian lingkungan dan kearifan budaya lokal yang pada akhirnya menumbuhkan jati diri dan memilikii rasa bangga dari penduduk setempat yang tumbuh akibat peningkatan kegiatan pariwisata. Hal 
Ni Kadek Ajeng Wangi Bhuanaputri, I Putu Ryan Dharma Putra, I Made Indra Wahyudi, Ni Made Ayu Cantika Ratih, Marcellino Dominicius Adam

tersebut membuktikan bahwa masyarakat di Desa Sidemen terlibat aktif dalam pengembangan dan pelestarian eksistensi Kain Songket Sidemen sebagai produk wisata yang unggul kreatif dan berbudaya, serta masyarakat Desa Sidemen yang dahulunya beralih profesi menjadi pekerja di bidang perhotelan saat ini di tengah pandemi COVID-19 banyak masyarakat lokal kembali terlibat aktif dalam proses pembuatan Kain Songket Sidemen. Dapat disimpulkan bahwa pengembangan Kain Songket Sidemen sebagai produk wisata sangat tergantung dalam pelibatan masyarakat lokal sesuai dengan konsep CBT (Community Based Tourism).

2. Kain Songket Sidemen sebagai Produk dengan Kearifan Budaya Lokal

Kearifan budaya lokal sendiri adalah pengetahuan lokal yang sudah sedemikian menyatu dengan sistem kepercayaan, norma, dan budaya serta diekspresikan dalam tradisi dan mitos yang dianut dalam jangka waktu yang lama. Kain Songket yang dihasilkan memiliki beragam motif yang didapat melalui contoh kain terdahulu maupun motif yang didapat dari sumber gambar yang sudah ada. Motif yang diberikan pada kain tenunan diantaranya kedis, boma, bulan, merak, wayang dan lain sebagainya. Motif kain songket Desa Sidemen yang digemari pelanggan kain tenun yaitu motif bulan, merak dan wayang, selanjutnya kain hasil tenunan yang didapatkan akan dikreasikan menjadi produk jadi sesuai dengan keperluan penggunanya. Kain songket Desa Sidemen ini dipasarkan dalam bentuk yang beragam sesuai dengan pesanan dari pelanggan, sehingga pendistribusian produk jadi yang merupakan hasil tenunan kain songket khas dari Desa Sidemen dapat dilakukan. Dengan mengembangkan potensi kain songket Desa Sidemen melalui usaha pemberdayaan diversifikasi yang ada sesuai dengan keinginan pasar eksistensi kain songket ini dapat dipertahankan. Serta adanya dinamisasi produk Kain Songket Sidemen sudah berubah seiring berjalannya globalisasi. Pembuatan Kain Songket Sidemen di masa kini sudah lebih dinamis dan digunakan dalam beragam acara fashion yang ada di beberapa daerah seperti Singapura dan Jepang. Pemanfaatan teknologi yang layak untuk diterapkan (Technologically Appropriate) adalah hal yang saat ini menjadi fokus utama dari pemerintah dalam upaya mendukung pariwisata berkelanjutan. Namun disisi lain menurut (Himawan, 2015) dalam tulisan yang berjudul E-Tourism: Antara Konsep dan Implementasi dalam Mendukung Industri Pariwisata Indonesia, mengutarakan bahwa keberadaan wisata digital di Indonesia merupakan suatu konsep yang baru dan masih belum mendapatkan perhatian penuh dari beberapa pihak. Pada hakikatnya internet memiliki peran penting dalam perkembangan teknologi, khususnya dalam bidang pariwisata, sehingga, korelasi antara internet dan media handphone sebagai alat komunikasi sangat bermanfaat bagi masyarakat. Dalam hal ini adapun konsep Community Based Tourism yang melibatkan partisipasi masyarakat untuk mengembangkan penjualan produk wisata berbasis kearifan budaya lokal melalui media digital untuk mendukung pariwisata berkelanjutan di Desa Sidemen. Pariwisata berbasis masyarakat berkaitan dengan adanya partisipasi yang aktif dari masyarakat sebagai pengeloladalam pembangunan kepariwisataan yang ada (Sunaryo, 2013). Konsep 
Konsep Community Based Tourism Sebagai Strategi Pengembangan Kain Songket Sidemen Di Bali

Comunity Based Tourism ini perlu didukung dengan konsep pemasaran yang efektif dan efisien dalam upaya penerapan pariwisata berkelanjutan.

\section{Kesimpulan}

Berdasarkan hasil pembahasan, dapat disimpulkan bahwa strategi pengembangan Kain Songket Sidemen sebagai produk wisata budaya dengan konsep Community Based Tourism mampu meningkatkan produk Kain Songket Sidemen Dewasa ini Kain Songket Sidemen mampu digunakan sebagai produk tradisional yang unik dan autentik menjadi produk semi modern tanpa menghilangkan pola motif dari Kain Songket Sidemen yang menjadi simbol kehidupan alam. 
Ni Kadek Ajeng Wangi Bhuanaputri, I Putu Ryan Dharma Putra, I Made Indra Wahyudi, Ni Made Ayu Cantika Ratih, Marcellino Dominicius Adam

\section{BIBLIOGRAFI}

Anoma, I. Putu, Mahagangga, I. Gusti Agung Oka, Ariwangsaa, I. Made Bayu, \& Wulandari, I. Gusti Ayu Athina. (2019). Reidentifikasi Konsep dan Teori Dalam Memahami Fenomena Blind Spot Penelitian Pariwisata di Bali.Google Scholar

Abdullah, I., Mujib, I., \& Ahnaf, M. I. (Eds.). (2008). Agama dan kearifan lokal dalam tantangan global. Sekolah Pascasarjana UGM. Google Scholar

Argyo, D., 2009. Pembangunan Pariwisata Berbasis Masyarakat. Surakarta : Sebelas Maret University Press. Google Scholar

Astuti, N. W. W., Yulianthi, A. D., Ginaya, G., \& Susyarini, N. P. W. A. (2020). Selling arak is a business opportunity in sidemen village. International journal of linguistics, literature and culture, 6(1), 32-41. Google Scholar

Atmaja, A.W.T.W., 2013. Perkembangan Motif Kerajinan Tenun Songket Di Desa Sidemen, Karangasem, Bali (Potensinya Sebagai Sumber Belajar Sejarah Kebudayaan Di SMA). Widya Winayata: Jurnal Pendidikan Sejarah, 1(1). Google Scholar

Byczek, C. (2011). Blessings for All? Community-Based Ecotourism in Bali Between Global, National, and Local Interests-A Case Study. Austrian Journal of SouthEast Asian Studies, 4(1), 81-106. Google Scholar

Chen, Jengchung Victor, Su, Bo chiuan, \& Widjaja, Andree E. (2016). Facebook C2C social commerce: A study of online impulse buying. Decision Support Systems, 83, 57-69. Google Scholar

Dolezal, C. and Novelli, M., 2020. Power in community-based tourism: empowerment and partnership in Bali. Journal of Sustainable Tourism, pp.1-19. Google Scholar

Gajdošík, T. (2018, April). Towards a conceptual model of intelligent information system for smart tourism destinations. In Computer Science On-line Conference (pp. 66-74). Springer, Cham. Google Scholar

Grüning, Björn, Dale, Ryan, Sjödin, Andreas, Chapman, Brad A., Rowe, Jillian, Tomkins-Tinch, Christopher H., Valieris, Renan, \& Köster, Johannes. (2018). Bioconda: sustainable and comprehensive software distribution for the life sciences. Nature Methods, 15(7), 475-476. Google Scholar

Hanum, F. (2020). Konsep Smart tourism sebagai Implementasi Digitalisasi di Bidang Pariwisata. Tornare: Journal of Sustainable and Research, 2(2). Google Scholar

Häusler, N., 2008, March. Community-based Tourism (CBT)-What works and what does not work? Drawing on experiences in South America and Asia. In 
International Conference on Responsible Tourism, 21-24 March, Kerala, India.Google Scholar

Himawan, Hidayatulah. (2015). E-tourism: Antara konsep dan implementasi dalam mendukung industri pariwisata Indonesia. Seminar Nasional Informatika (Semnasif), 1(5). Google Scholar

Helmita, H., Sari, O. N., Julianti, N. T., \& Dwinata, J. (2021). Pengembangan Desa Wisata Berkonsep Smart tourism Melalui Pemberdayaan Kompetensi Masyarakat Desa Pujorahayu. GEMA: Jurnal Gentiaras Manajemen dan Akuntansi, 13(1), 37-49. Google Scholar

Kasman, S. (2011). Komodifikasi Kesenian Tradisional Wacana Estetika Posmodern dalam Pariwisata. Ekspresi Seni: Jurnal Ilmu Pengetahuan dan Karya Seni, 13(2). Google Scholar

Kurniadi, B. S. (2011). Dampak Ekonomi Pariwisata Dari Penerapan Konsep Community Based Tourism (Cbt). UNS-F.Ekonomi Jur Ekonomi Pembangunan -F.0107035-2011. Google Scholar

Puspitasari, Chory, Prayudi, Paryudi, \& Rochayanti, Christina. (2020). Pengembangan Model Komunikasi Dalam Pengelolaan Obyek Wisata. Paradigma: Jurnal Masalah Sosial, Politik, Dan Kebijakan, 24(1), 512-521. Google Scholar

Triwardani, R. and Rochayanti, C., 2014. Implementasi Kebijakan Desa Budaya dalam Upaya Pelestarian Budaya Lokal. Reformasi, Jurnal ilmu sosial dan Ilmu Politik 4(2). Google Scholar

Yulyantari, L.M. and Adh, I.P.W., 2016. Iptek Bagi Produk Eksporkerajinan Songket Motif Bali Di Kabupaten Karangasem Bali. Prosiding Semnas Hasil Pengabdian Masyarakat. Google Scholar

\section{Copyright holder:}

Ni Kadek Ajeng Wangi Bhuanaputri, I Putu Ryan Dharma Putra, I Made Indra Wahyudi, Ni Made Ayu Cantika Ratih, Marcellino Dominicius Adam (2021)

\section{First publication right:}

Syntax Idea

\section{This article is licensed under:}

